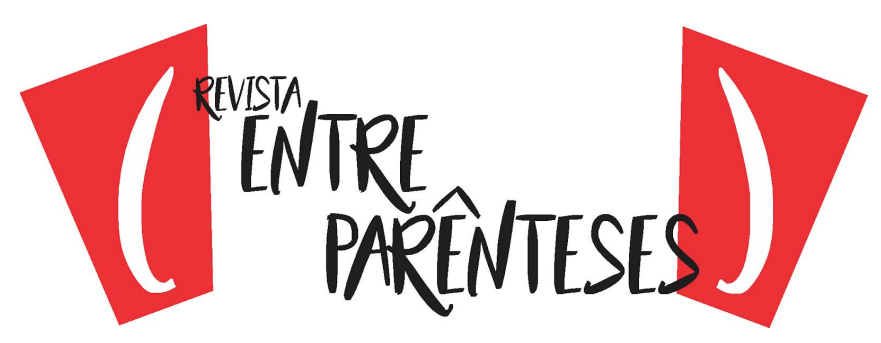

\title{
O ENSINO BILÍNGUE EM MOÇAMBIQUE: HETEROGENEIDADE LINGUÍSTICA E PROPOSTA DE ABORDAGEM DO ENSINO-APRENDIZAGEM DO PORTUGUÊS
}

\author{
Artinésio Widnesse SAGUATE ${ }^{1}$ \\ Universidade de São Paulo - USP - SP \\ (artinesiow@gmail.com)
}

\begin{abstract}
Resumo: Neste artigo discuto o Ensino Bilíngue em Moçambique, particularmente a heterogeneidade linguística entre o português e o emakhuwa e a metodologia de abordagem do ensino-aprendizagem do português nesse contexto. Para mostrar essa heterogeneidade linguística, tomo como exemplo algumas ocorrências morfossintáticas, extraídas de textos escritos por alguns alunos da $7^{\text {a }}$ classe $\left(7^{\text {a }}\right.$ série) de duas escolas de Nampula (norte do País). Já com relação à abordagem metodológica, destaco as práticas corretivas dos respectivos professores no ensino-aprendizagem do português.Em termos teóricos, baseio-me na teoria do dialogismo (BAKHTIN, 1992) e, também, na teoria da variação linguística (LABOV, 1972). Sugiro que a abordagem do ensino-aprendizagem do português L2 num contexto de Ensino Bilíngue em Moçambique requer, primordialmente, uma análise contrastiva dessa língua em relação à língua nativa envolvida no processo.
\end{abstract}

Palavras-chave: Moçambique; heterogeneidade linguística; ensino bilíngue; ensino de português.

\begin{abstract}
In this article I discuss Bilingual Education in Mozambique, particularly the linguistic heterogeneity between Portuguese and emakhuwa and the Portuguese teaching-learning approach methodology in this context. In order to show this linguistic heterogeneity, I take as an example some morphosyntactic occurrences, extracted from texts written by some 7th grade students from two schools in Nampula (north of the country). Regarding the methodological approach, I highlight the corrective practices of the respective teachers in the teaching-learning of Portuguese. In theoretical terms, I rely on the theory of dialogism (BAKHTIN, 1992) and also on the theory of linguistic variation (LABOV, 1972). I suggest that the teaching-learning approach of Portuguese-L2 in a context of Bilingual Education in Mozambique requires, first of all, a contrastive analysis of that language in relation to the native language involved in the process.
\end{abstract}

Keywords: Mozambique; linguistic heterogeneity; bilingual education; teaching of Portuguese.

Resumen: En este artículo se discute la educación bilingüe en Mozambique, la heterogeneidad lingüística en particular entre el portugués y Emakhuwa y la metodología del enfoque de enseñanza-aprendizaje de portugués en este contexto. Para mostrar esa heterogeneidad lingüística, tomo como ejemplo algunas ocurrencias morfosintácticas, extraídas de textos escritos por algunos alumnos de la $7^{\mathrm{a}}$ clase ( $7^{\mathrm{a}}$ serie) de dos escuelas de Nampula (norte del país). En cuanto al enfoque metodológico, se destacan las prácticas correctoras de sus profesores en la enseñanza del portugués. En términos teóricos, me baso en la teoría del dialogismo (BAKHTIN, 1992) y, también, en la teoría de la variación lingüística (LABOV, 1972). Sugiero que el enfoque de la enseñanza y el aprendizaje del portugués - L2 en el contexto de la educación bilingüe en Mozambique requiere ante todo un análisis contrastivo del lenguaje en relación con la lengua nativa implicados en el proceso.

Palabras clave: Mozambique; heterogeneidad lingüística; enseñanza bilingüe; la enseñanza del portugués.

1Doutor em Filologia e Língua Portuguesa pela Universidade de São Paulo, artinesiow@gmail.com. Docente na Universidade Pedagógica - Delegação de Nampula, UPN, Moçambique. 


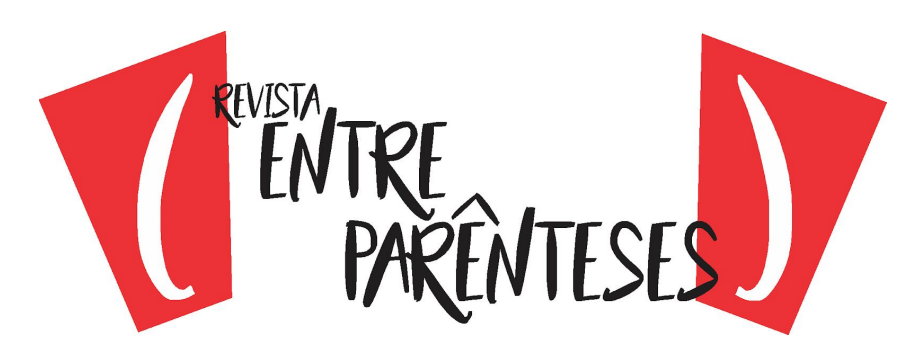

\section{INTRODUÇÃO}

Este artigo aborda o Ensino Bilíngue em Moçambique. ${ }^{2}$ Interessa-me a heterogeneidade linguística entre o português e o emakhuwa ${ }^{3}$ e a metodologia de abordagem do ensino-aprendizagem do português nesse contexto. Tomo como dados de análise e demonstração, por um lado, o português escrito por alunos da $7^{\text {a }}$ classe ( $7^{a}$ série) de duas escolas de Nampula (norte de Moçambique): Escola Primária de Anchilo-Sede e Escola Primária Completa de Mulapane I e, por outro, a prática dos professores de português dessas escolas. Com base nos dados analisados e nas observações no terreno, foi possível observar, por um lado, uma série de dificuldades enfrentadas pelos alunos na aprendizagem do português e, por outro, dificuldades de abordagem do ensino do português pelos professores. Assim, constituem objetivos deste artigo: a) apresentar o cenário do Ensino Bilíngue nessas escolas; b) mostrar a escrita do português das crianças; c) propor caminhos teóricos e práticos de abordagem do ensino-aprendizagem do português.

\section{O CENÁRIO DE ENSINO-APRENDIZAGEM DA ESCRITA DO PORTUGUÊS NO ENSINO BILÍNGUE}

Qualquer ensino-aprendizagem será infrutífero se não encontrar no professor abordagem adequada. No caso do Ensino Bilíngue em Moçambique, particularmente do ensino-aprendizagem do português, é possível observar algumas áreas em que os alunos enfrentam maiores dificuldades. Entretanto, muitas vezes, os professores se valem de estratégias transportadas do ensino monolíngue e,

\footnotetext{
${ }^{2}$ Este artigo constitui recorte da tese de doutorado, defendida pelo autor na Universidade de São Paulo - Brasil.

${ }^{3}$ Segundo o Censo Geral da População e Habitação realizado em 2007, além do português, Moçambique tem mais de dezasseis línguas nativas de origem bantu, uma das quais é o emkhuwa, praticado na região norte do País.
} 


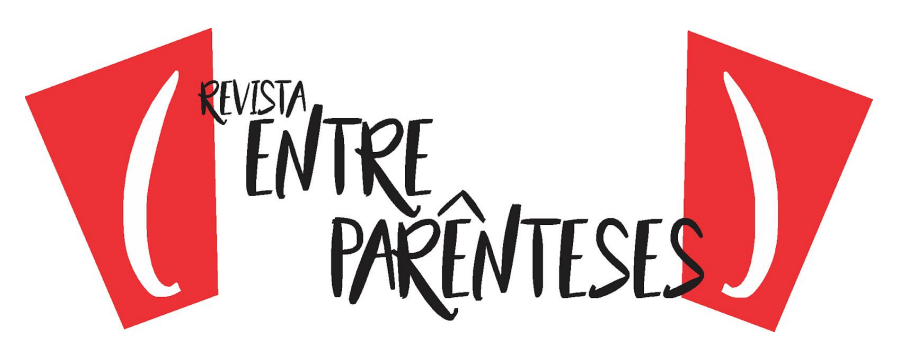

quando se deparam com questões próprias do Ensino Bilíngue, os professores tendem a recorrer a improvisos. Para tanto, entendo que, no Ensino Bilíngue, a escola deve primar por maior potencialização do professor e de seus instrumentos de trabalho com vista a uma melhor viabilização do processo de ensino-aprendizagem. É claro que, nos casos em que o processo de ensino-aprendizagem do português envolve questões estruturais da língua, a prática didática recorre ao material didático distante da realidade moçambicana. Concretamente, têm sido adotadas gramáticas do contexto europeu. São gramáticas úteis, sem dúvida, para o conhecimento do funcionamento do português no contexto europeu. Portanto, até certo ponto, elas podem conter limitações no ensino-aprendizagem do português no contexto moçambicano, particularmente no contexto de Ensino Bilíngue. Não raras vezes, com base nessas gramáticas, 0 ensino-aprendizagem, no contexto moçambicano,limita-se em observar o que está "correto", ou "errado", na fala/escrita de uma criança. Ou seja, no que parece, não tem sido levado a cabo uma análise profunda sobre as razões que fazem com que uma criança fale/escreva um português que se mostra diferente daqueles contextos, sobretudo do contexto europeu.

Entretanto, ao depender de um material didático cujo ideal linguístico se mostra distante do contexto de ensino-aprendizagem dos alunos, o ensino moçambicano tende a propiciar insegurança (linguística) na prática do próprio português, pois se centra em práticas corretivas e, não raras vezes, punitivas, criando, de certo modo, sentimento de incapacidade e de incompetência por parte das crianças. A tendência exacerbada de evitar tudo o que se considera estranho ao português de referência, sobretudo a presença das marcas das línguas nativas moçambicanas,é inadequada para o ensino-aprendizagem em contexto de Ensino Bilíngue. Essa tendência deixa à margem o fato de que a língua é um campo dinâmico e vivo, em função de somente ser falada/escrita por pessoas vivas (cf. BAGNO, 1999). Portanto, a tendência de se "ensinar" o "português puro" submete o aluno a uma situação de combate contra o que lhe é intrínseco: a sua própria matriz 


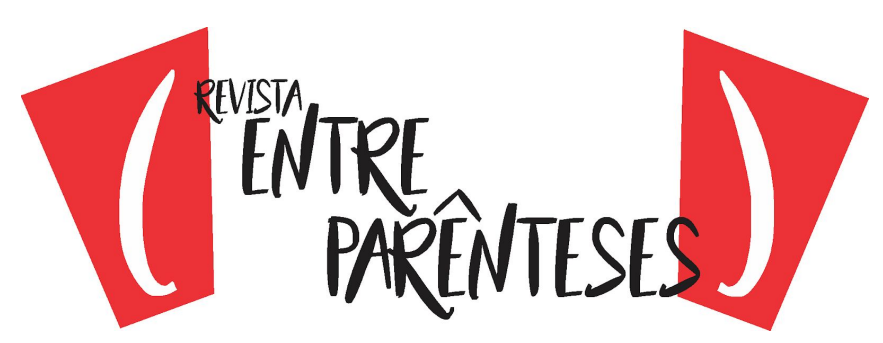

linguística, que é, basicamente, das línguas nativas moçambicanas. É necessário, portanto, considerar o fato de que o português praticado no contexto europeu será sempre diferente do praticado no contexto moçambicano, porque, aliás, trata-se de contextos diferentes e, por isso, de modos de uso de língua igualmente diferentes. Desse modo, a concepção de qualquer material sobre o ensino-aprendizagem do português em Moçambique, particularmente no contexto de Ensino Bilíngue, deve ter em conta a situação linguística do País; isto é, a heterogeneidade entre o português e as línguas nativas, em que algumas manifestações podem ser conferidas adiante.

\section{METODOLOGIA USADA E OPÇÕES TEÓRICAS}

Para mostrar a heterogeneidade da língua no Ensino Bilíngue português-emakhuwa tomo como exemplo algumas ocorrências morfossintáticas, extraídas de textos escritos por alguns alunos da $7^{\text {a }}$ classe das escolas mencionadas e, de forma genérica, as práticas corretivas dos respectivos professores.Em termos teóricos, e de forma geral, baseio-me na teoria do dialogismo (BAKHTIN, 1992), uma vez que, no Ensino Bilíngue, a heterogeneidade desencadeia inevitavelmente um diálogo entre o português e a língua nativa envolvida, entre o sujeito e sua relação com a língua. Baseio-me também na teoria da variação linguística (LABOV, 1972), concretamente nos moldes em que o contato entre línguas em um contexto bilíngue ou multilíngue pode originar influências mútuas na forma das línguas envolvidas (CALVET, 2002). Portanto, a abordagem da heterogeneidade é considerada em dois aspectos: língua (o português), relação entre línguas (português-emakhuwa).

Em primeiro lugar, trata-se, portanto, de considerar que a heterogeneidade da língua, considerada cada língua particular (o português, o emakhuwa etc.), caracteriza-se, segundo Labov (1972), pelo uso das formas 


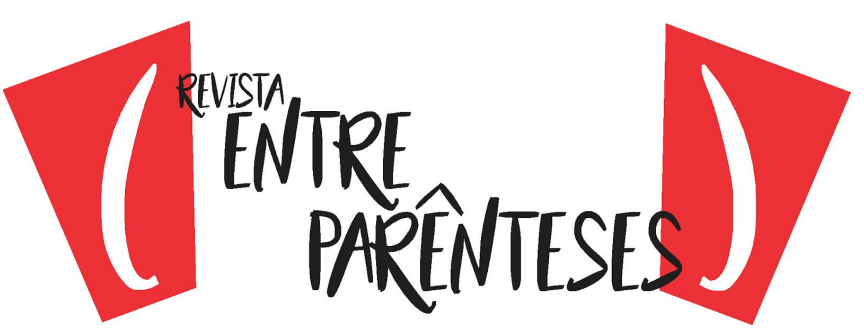

linguísticas, que se correlaciona com fatores linguísticos e extralinguísticos. ${ }^{4} \mathrm{Em}$ segundo lugar, trata-se de considerar a heterogeneidade entre línguas, em que na coexistência de duas ou mais línguas transparecem, em cada uma das línguas, ou em uma delas, certos elementos, certas normas, certos usos, certas características de outra língua em contato. Assim, uma análise do português, ou de uma língua nativa, em Moçambique deve ser considerada com base no fato de que cada uma dessas línguas não funciona em um campo isolado, mas, conforme já avançado, em um campo de contato, o que configura uma heterogeneidade entre línguas. Por conta dessa heterogeneidade, formas linguísticas e fatos discursivos de cada uma das línguas em contato estão em diálogo uns com outros. E esse diálogo ganha significação no discurso, seja na fala, seja na escrita.Em suma, a relação entre o português e as línguas nativas deve ser encarada como de diálogo, em que nenhuma das línguas pode ser abordada de forma descolada da outra.

\section{ALGUMAS MARCAS DE HETEROGENEIDADE ENTRE O PORTUGUÊS E O EMAKHUWA: Aspectos morfossintáticos: concordância verbal}

Observem-se os seguintes casos:

(1) [...] alque [alguém] que não sabem ler Emakhuwa (EBM1.1, grifos meus).

(2) $O$ português e poa [boa] Iguaa[língua]quise[que se]falao [falam] em [rasura] Moçambeque (EBA6.1, grifos meus).

Conforme se pode observar nos exemplos, ocorre desvio de concordância verbal, em que o número do pronome, ou do nome-sujeito, não concorda com o número da forma verbal. Ou seja, a partir de um sujeito no singular

\footnotetext{
${ }^{4}$ Contudo, essa concepção de que fatores extralinguísticos é aqui reformulada, considerando-se, portanto, a heterogeneidade da língua como caracterizada por fatores linguísticos e discursivos (históricos, sociais e ideológicos), esses últimos vistos como também constitutivos da língua (BAKHTIN, 1992) e não como extralinguísticos.
} 


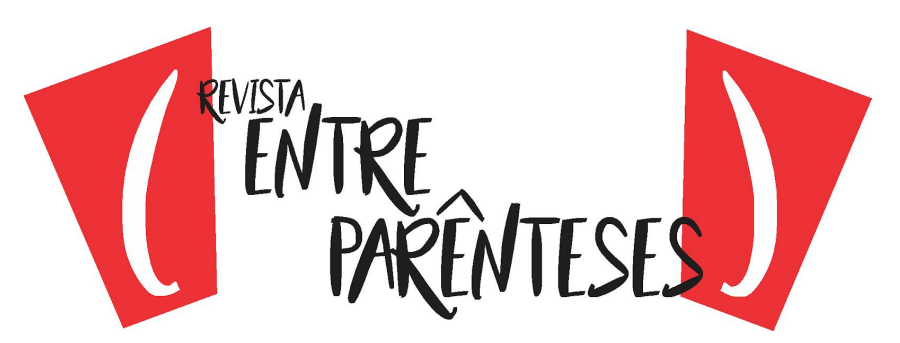

("alguém"; "língua"), a forma verbal é articulada para o plural ("sabem"; "falam", respectivamente). Pode-se reexaminar os exemplos tomando em consideração a estrutura do emakhuwa para observar até que ponto o desvio das formas linguísticas do português remete também à presença das marcas dessa língua (o emakhuwa):

(3) [...] akala [aakhala] ahisuela [ahinsuwela] oler [oleri] Emakhuwa (EBM1.1, grifos meus).

O exemplo em (3) corresponderia à construção, em português, alguém que não sabem ler emakhuwa (EBM1.1, grifos meus), feita pelo mesmo escrevente. Assim, analisando a estrutura desse exemplo, tem-se o seguinte:

- A palavra "aakhala" é uma forma do verbo okhala ("haver", "existir") na $3^{a}$ pessoa do plural. Essa e outras formas do mesmo verbo permitem subentender o nome-objeto direto, sem, no entanto, criar dificuldades de reconhecimento do tal nome-objeto direto em referência e sem criar qualquer incompreensão no sentido da frase, pois a própria forma do verbo da oração complementar, em articulação com o predicado, permite tal reconhecimento e entendimento. No caso, o nome-objeto direto é "gente", isto é, um número indeterminado de pessoas.

- Já em ahinsuwela,ocorrem quatro morfemas: a- $(=\mathbf{a}-+\mathbf{a}-)^{6}+\mathbf{h i}-+-(\mathbf{n})$ suwel $^{7}$. Os três primeiros morfemas (a-; a-; hi-) são presos e o último (-(n)suwela) é livre. O primeiro (morfema preso a-) constitui um pronome relativo com a função de retomar o nome-objeto direto "gente". Portanto, em português, equivaleria ao pronome relativo "que". Já o segundo (morfema preso a-) representa a forma conjugada do verbo na $3^{a}$ pessoa do plural (aa-suwela "sabem"). O terceiro (morfema preso hi-) constitui uma forma negativa, que,

\footnotetext{
${ }^{5}$ Outras formas do verbo okhala: kookhala, wookhala, ookhala $\left(1^{\mathrm{a}}, 2^{\mathrm{a}}\right.$ e $3^{\mathrm{a}}$ pessoas do singular, respectivamente), nookhala, mookhala, aakhala $\left(1^{\mathrm{a}}, 2^{\mathrm{a}}\right.$ e $3^{\mathrm{a}}$ pessoas do plural, respectivamente).

${ }^{6}$ Portanto, a-, nesse contexto, conserva dois morfemas.

${ }^{7} \mathrm{O}$ " $\mathrm{n}$ " entre parênteses significa que ele pode ocorrer como parte do radical ou não, conforme a forma conjugada.
} 


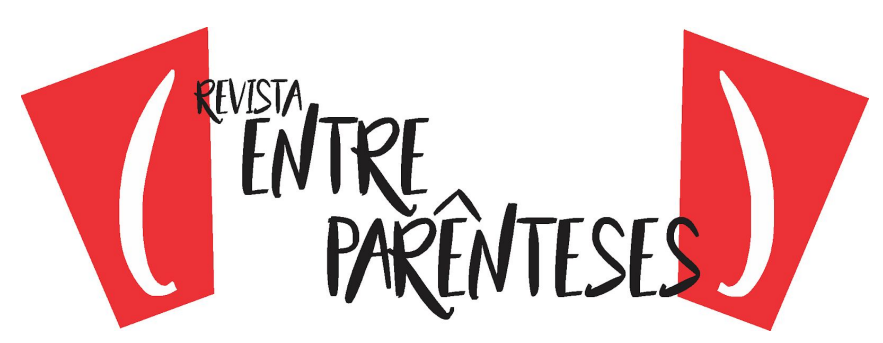

em português, equivaleria dizer "não". Já o último (morfema livre) é um verbo, que, em português, significaria "saber".

Assim, em uma tradução livre, teríamos a seguinte frase:

(4) [...] há [gente] que não sabem ler emakhuwa,

em que se podem observar duas orações: uma principal e outra complementar. A oração principal, [...] há gente, compreende a forma verbal e o nome-objeto direto "gente" - um número indeterminado de "pessoas". Por indicar um número indeterminado de pessoas, "gente" nos remete ao plural. A oração complementar: que não sabem ler Emakhuwa compreende um pronome relativo-sujeito "que", que retoma o nome-objeto direto "gente", que, como disse, nos remete a um número indeterminado e plural de "pessoas". Por ser um sujeito-plural, ele se articula necessariamente com a $3^{a}$ pessoa do plural no verbo (saber> sabem). Note-se a passagem da forma "gente" para "alguém", cuja associação se justifica pelo traço de indefinição do agente, sendo talvez essa indefinição confundida com a imprecisão da quantidade na palavra "gente".

Algo similar ocorre no exemplo em (5) seguinte:

(5) [...] sintteneroso cala emlavuliyaa[enlavuliya]mulaboni [mulaponi] seio [seiyo] as molumunkhuni (EBA6.1, grifos meus).

A expectativa seria que, nessa sentença, ocorresse correspondência estrutural e de sentido em relação à mesma construção no português ( $O$ Português é boa línguaque se falam em Moçambique (EBA6.1, grifos meus)). Porém, aqui não ocorre essa correspondência. Assim: 


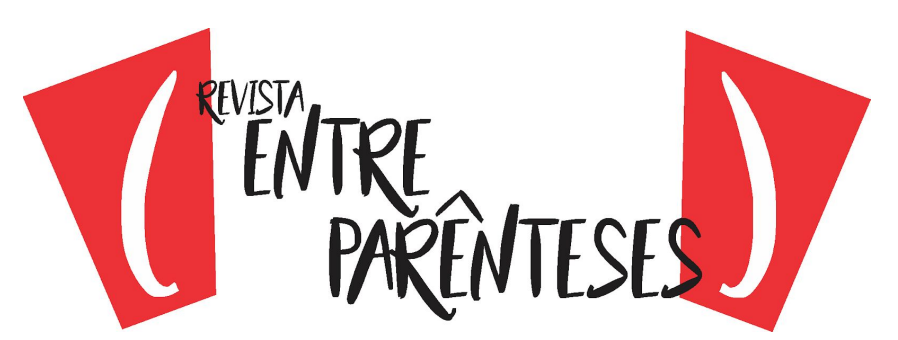

- os primeiros dois elementos: "sintteneroso" e "cala" não foi possível decifrá-los;

- o terceiro elemento: "enlavuliya" é morfologicamente constituído por três morfemas: en-(+)-lavul-(+)-iya. O primeiro, en-, constitui um morfema preso e equivaleria, em português, ao pronome relativo que. Porém, diferentemente do pronome relativo a-, apresentado anteriormente, em que há retomada do nome no plural, en- estaria retomando um nome no singular. O segundo, -lavul- ${ }^{8}$, se apresenta como morfema livre, e significaria, em português, fala. Já o terceiro e último, -iya-, se apresenta como morfema preso, equivalendo, em português, ao pronome reflexivo se;

- o quarto e quinto elementos ("mulaponiseiyo") devem ser analisados e traduzidos conjuntamente, sendo que: "mulaponi" é constituído por dois morfemas: mu- - morfema preso, que equivaleria à partícula locativa em; -elapo- - morfema livre, que equivaleria a dizer país, região;-ni morfemapreso, que reforçaria o locativo em. Já "seiyo" equivaleria ao demonstrativo este;

- os últimos dois elementos (“as molumunkhuni”), não foi possível decifrá-los.

Como se pode depreender, o terceiro, o quarto e o quinto elementos da estrutura permitem afirmar que se trata de uma tentativa de "tradução" do português para o emakhuwa do enunciado em (2): O português é boa línguaque se falam em Moçambique, em que: "enlavuliya" equivaleria a que se falam (enlavuliya é uma forma verbal no plural - $3^{a}$ pessoa); e“mulaponiseiyo" (neste país) equivaleria a Moçambique. O português é, portanto, a língua que se fala no país - Moçambique. Entenda-se o país como um lugar constituído por gente, por pessoas (no plural). São

\footnotetext{
${ }^{8} \mathrm{~A}$ partir desse morfema, derivam palavras como: o-lavula = "falar", oo-lavula = "falou", on-lavula = "que fala", on-lavul-iha = "que faz falar".
} 


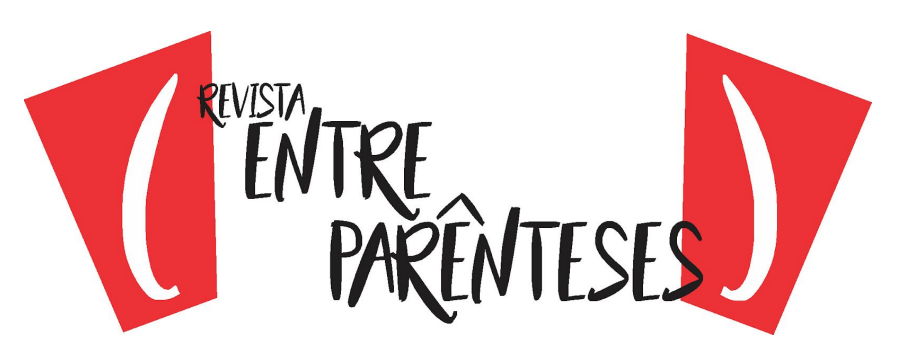

essas pessoas que falam, portanto, essa língua. Esse entendimento justificaria a opção do verbo na $3^{a}$ pessoa do plural: falam, por conta da tentativa de corresponder a estrutura e o sentido do emakhuwa para o português (e não necessariamente de uma construção primeira em português, cujo resultado é o desvio morfossintático em relação à variedade de referência).

O que se pode observar nesses exemplos é que, apesar de a redação nas duas línguas não significar, necessariamente, uma tradução literal de uma língua para outra, o que ocorreu na construção morfossintática do português foi, a fundo, uma transposição, de estrutura e de sentido, de uma construção morfossintática do emakhuwa para essa língua (o português). Isso já ficou demonstrado, operando um movimento de enunciação (e recuperando todos os elementos da estrutura): do emakhuwa para o português. Ou seja, quando considerada a construção morfossintática no português em si só, ela mostra desvio (de concordância verbal) em relação à variedade de referência. Porém, quando a mesma construção do português é considerada em relação ao emakhuwa, o desvio morfossintático (no modo de concordância verbal, em relação à variedade de referência do português) deixa de existir, ou, pelo menos, ganha explicação.

Outro exemplo bastante presente na fala do português da maioria dos moçambicanos (e que, apesar de não aparecer nos dados, merece menção) é a oposição entre "dar à luz" e "nascer". Diferentemente do português europeu, em que se observa uma distinção vocabular, isto é, oposição entre o ato pelo qual se passa a ter vida, dito através da expressão "dar à luz" e o fato de passar a ter vida, dito através do vocábulo "nascer", essa distinção vocabular tende a não se observar no português praticado em Moçambique. Isto é, usa-se, genericamente, o vocábulo "nascer" para os dois acontecimentos. Por exemplo, diz-se "Minha irmã nasceu um menino", ou, simplesmente, "Minha irmã nasceu", o equivalente a dizer, na variedade europeia, "Minha irmã deu à luz a um menino", ou, simplesmente, "Minha irmã deu à luz". Mas, também, diz-se "Minha irmã nasceu", no sentido da variedade europeia. Contudo, esse dizer na variedade do português praticado em Moçambique tem sido 


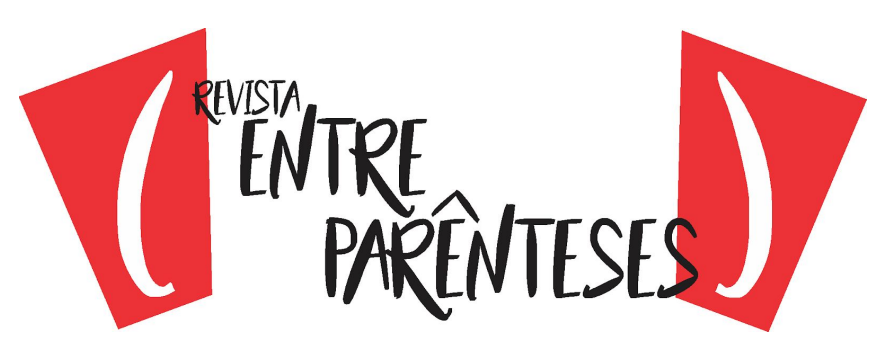

considerado como erro (sobretudo por aqueles que se consideram praticar a variedade europeia). No entanto, antes de mais, essa não distinção vocabular parece ter origem na organização morfossintática das próprias línguas nativas, o que permite sua transposição para o português. Tomando como exemplo o elomwe, diz-se oyara - "dar à luz" -, oyariwa - "nascer" -, ooyariwa/oyariwe - nasceu (pretérito perfeito do indicativo). Conforme se pode observar, o que ocorre, portanto, é a distinção entre "dar à luz" e "nascer", a partir da flexão de uma mesma palavra.

Estas constatações permitem afirmar o seguinte:

i) a heterogeneidade linguística em Moçambique se manifesta como constitutiva na relação português-línguas nativas. Desse modo, não é exclusivamente uma língua a força fundadora do português escrito pelos alunos do Ensino Bilíngue, mas o diálogo entre línguas (entre o português e línguas nativas, caso do emakhuwa);

ii) na heterogeneidade entre o português e o emakhuwa, é, essencialmente, em emakhuwa o lugar de enunciação dos alunos, inclusive no tocante à representação escrita. Desse modo, questões de ordem linguístico-discursiva localizáveis nos textos se explicam, primordialmente, pelas características da língua nativa.

\section{PROPOSTA DE ABORDAGEM DO ENSINO-APRENDIZAGEM DO PORTUGUÊS}

A abordagem do ensino-aprendizagem do português - L2 num contexto de Ensino Bilíngue em Moçambique requer, primordialmente, uma análise contrastiva dessa língua em relação à língua nativa envolvida no processo. Esse exercício passa necessariamente pela descrição comparativa e/ou paralela das línguas em questão. $O$ resultado dessa descrição pode ser capaz de determinar qual objeto de ensino-aprendizagem merece maior atenção. Nesse caso, é imprescindível 


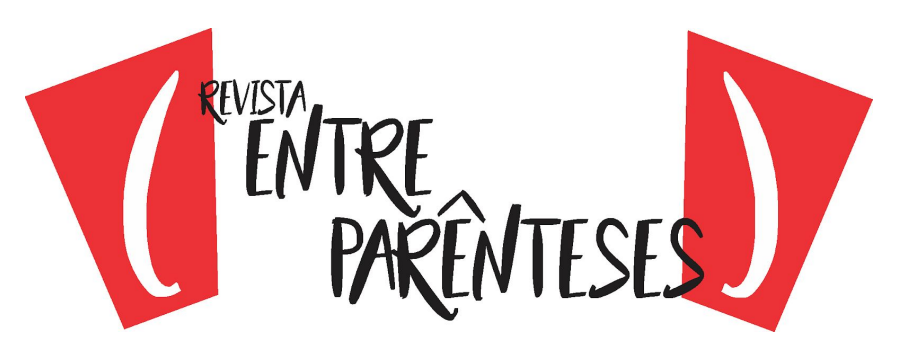

que os professores de Ensino Bilíngue tenham conhecimento sobre a estrutura da língua nativa dos alunos e os resultados de uma análise comparativa das línguas envolvidas com vista a descortinar as diferenças entre as estruturas dessas línguas e a destacar as áreas que mais provavelmente oferecerão dificuldades a seus alunos; estar apto a organizar um plano de aula baseado nesses dados e a dar-lhes a devida ênfase (sem, contudo, ignorar as outras áreas que não apresentam dificuldades.

Por exemplo, nos aspectos morfossintáticos, seu ensino partiria, portanto, da descrição da variedade em uso, em contraste com a variedade de referência e, também, em contraste com a estrutura das línguas nativas (caso do emakhuwa) em contato com o português. O objetivo seria levar os alunos a entenderem os sentidos em estruturas mais ou menos complexas da língua. Por exemplo, na construção "O português [...] língua que se falam", o professor demonstraria que a palavra destacada denotaria, tanto na língua de chegada quanto na língua de partida, forma verbal na $3^{a}$ pessoa do plural. O professor chamaria atenção para o fato de que, apesar dessa semelhança, a diferença nas duas línguas residiria, porém, na construção morfossintática (incluindo no significado). Assim, o professor explicaria que, enquanto na variedade de referência do português a construção "O português [...] língua que se falam" se mostra estranha e, portanto, não aceita, na variedade de referência do Emakhuwa, ela é perfeitamente aceita, na estrutura e no sentido. $O$ professor formularia a mesma construção em emakhuwa, destacando a forma verbal "falam", que seria "enlavuliya" (cujo verbo é "olavula") e demonstraria, portanto, que essa forma verbal corresponde à flexão do verbo no plural, em que a forma verbal subentende, ao mesmo tempo, o sujeito e o objeto, isto é, "quem fala" e o "que fala". Nesse caso, "quem fala" seria um sujeito comum: gente, que, pelas características de número, denotaria mais de uma pessoa, cuja correspondência no português seria: "gente de Moçambique"; pelo que, provavelmente, ao aluno estaria transpondo essa construção morfossintática do emakhuwa para o português. 


\section{CONSIDERAÇÕES FINAIS}

Com base nesta breve incursão pelo funcionamento da heterogeneidade linguística entre o português e o emakhuwa em Moçambique, vale considerar que as ações de abordagem do ensino-aprendizagem do português no Ensino Bilíngue devem privilegiar a heterogeneidade linguístico-discursiva entre o português e as línguas nativas; o que passa pela descrição das línguas moçambicanas (incluindo da prática real do português no País); descrição da abordagem do ensino-aprendizagem das línguas no Ensino Bilíngue; análise, de forma crítica, dos fatores que atuam no processo de ensino-aprendizagem das línguas no Ensino Bilíngue - uma das quais é, sem dúvida, a própria heterogeneidade da língua e a própria heterogeneidade entre as línguas; aliar a teoria à prática, isto é, através de ações concretas que visem ajudar os professores no ensino-aprendizagem das línguas (particularmente do português) no Ensino Bilíngue.

\section{REFERÊNCIAS}

BAGNO, M. Preconceito Linguístico: o que é, como se faz. São Paulo: Loyola, 1999.

BAKHTIN, M. Estética da Criação Verbal. São Paulo: Martins Fontes, 1992.

CALVET, J. L. Sociolinguística: uma introdução crítica. Tradução Marcos Marcionilo. São Paulo: Parábola Editorial, 2002.

LABOV, W. Sociolinguistic Patterns. Philadelphia/PA: University of Pennsylvania Press, 1972.

SAGUATE, A. W. O Português Makhuwa: representação escrita e proposta de exercícios didáticos no ensino bilíngue. Tese (Doutoramento). Faculdade de Filosofia, Letras e Ciências Humanas da Universidade de São Paul, 2017.

Recebido em 02/07/2018.

Aceito em 27/08/2018. 